\title{
DETERMINATION OF TEMPERATURE DISTRIBUTION ON WINDINGS OF OIL TRANSFORMER BASED ON THE LAWS OF HEAT TRANSFER
}

\author{
Volodymyr Grabko' ${ }^{1}$,Stanislav Tkachenko ${ }^{2}$, Oleksandr Palaniuk ${ }^{3 凶}$ \\ ${ }^{1}$ Department of Electromechanical Systems Automation in Industry and Transport, Vinnytsia National Technical University, Vinnytsia, \\ Ukraine \\ ORCID: https://orcid.org/0000-0002-4666-1758 \\ ${ }^{1}$ Department of Heat Power Engineering, Vinnytsia National Technical University, Vinnytsia, Ukraine \\ ORCID: https://orcid.org/0000-0002-4904-4608 \\ ${ }^{1}$ Department of Electromechanical Systems Automation in Industry and Transport, Vinnytsia National Technical University, Vinnytsia, \\ Ukraine \\ ORCID: https://orcid.org/0000-0003-3413-9839 \\ $\triangle$ Corresponding author: Oleksandr Palaniuk,e-mail: oleksanderp020895@gmail.com
}

A R T ICLE INFO
Article history:
Received date 14.09 .2021
Accepted date 21.10 .2021
Published date 29.10 .2021
Section:
Energy
D O I

$10.21303 / 2313-8416.2021 .002140$

KEYWORDS

transformer

thermal conductivity

insulation

temperature heating

modeling cooling heat transfer

heat

heat release

conductor

prediction

measurement

\section{ABSTRACT}

The object of research: development of a technology for determining the temperature of the winding of a power oil transformer, in particular, the analysis of thermal processes in the winding of a power transformer during short-term overloads, taking into account the influence of the environment.

Investigated problem: temperature distribution in the winding of a power oil transformer taking into account short-term load surges in the problem of assessing the residual life of the insulation of the transformer winding by temperature aging. The calculation of the temperature distribution in the winding was carried out using the passport data and characteristics of the power oil transformer, including the winding, transformer oil, load currents.

The main scientific results: mathematical model was calculated, with the help of which the results of temperature distribution in the transformer winding were obtained during short-term load surges or constant work with an increased load. According to the presented model, the analysis of the cooling time of the transformer winding after short-term overloads is carried out. Comparing the results obtained on the simulation model with the known results of experimental studies of the temperature distribution in the winding of a power transformer, the adequacy of the mathematical model is proved. It is shown that the use of the laws of heat transfer in a homogeneous plate to analyze the temperature distribution in the transformer winding is not wrong, but requires clarifications and simplifications.

The area of practical use of the research results: enterprises of the machine-building industry and energy companies specializing in the production and operation of transformer equipment. Innovative technological product: simulation model of heat distribution in a transformer winding, which can take into account the load of the transformer, the effect of the environment on the insulation of the transformer windings.

Innovative technological product: a method for diagnosing the duration of the non-failure operation of a transformer, which makes it possible to ensure trouble-free operation and save money for the repair of transformer equipment.

Scope of the innovative technological product: design and development of diagnostic systems for windings of power oil transformers.

(C) The Author(s) 2021. This is an open access article under the Creative Commons CC BY license

\section{Introduction}

\section{1. The object of research}

Development of technology for determining the temperature of the winding of a power oil transformer, in particular, the analysis of thermal processes in the winding of a power transformer during short-term overloads, taking into account the impact of the environment.

\section{2. Problem description}

Power transformers belong to the main electrical equipment of electrical networks and systems through which electricity flows are transmitted [1]. 
High-power power transformers are among the most valuable assets in the electrical grid system. This means that considerable attention has been paid to such transformers to determine the operating life. Emergency shutdown of power transformers affects the stability of the network and leads to significant financial costs for energy enterprises and the electrical network as a whole. The insulation of the transformer winding is the most vulnerable element during transformer overloads, therefore

When a power transformer is in operation, some of the electrical energy is converted into heat. And although this part of the energy is quite small in comparison with the total electrical power and the flows of electrical energy transmitted through the transformer, the extreme modes that occur in power transformers cause a significant increase in temperature, which affects the exhaustion of the working life of the winding insulation. Therefore, the urgent task is to determine how the temperature of the windings changes during operation, taking into account emergency short-term operating modes.

A number of methods and means are known that allow assessing the aging process of the insulation of the windings of power transformers during their operation [2, 3]. However, these approaches are focused on tracking slowly changing processes.

At the same time, power transformers often operate in modes of short-term increased loading or overload, which can be assessed by the dynamic modes of their operation with a certain delay after the end of the corresponding process. These modes of operation make a significant correction in the process of determining the residual working life of the insulation of power transformers.

An approach is known according to which it is assumed to determine the temperature of the hottest point of the winding insulation, according to which it is possible to evaluate the process of thermal aging of the windings of a power transformer.

The procedure for calculating the temperature of the hottest point is given in international standards [4, 5]. In [6], an algorithm is presented for calculating the temperature of the hottest point of a loaded transformer using experimental data obtained in a short time of heating the windings. The specified method for determining a hotter point in a power transformer is provided by determining the heat transfer differential, in the calculation base of which the winding is considered as a cylinder without taking into account the dependence of temperature on spatial coordinates [7].

There is no method that will allow indirect measurements without the use of various kinds of sensors to determine how much heat is released at the edge of the winding and what is the temperature of the winding.

A method is proposed for analyzing the temperature at the edge of the winding, based on the processes of heat transfer of a rectangular conductor with an internal heat source, which is completely washed by a liquid. The source of internal heat is an electric current flowing through the conductor. This approach requires the calculation of the heat transfer coefficients used in the energy (thermal) equation. The mathematical model allows you to determine the temperature with an arbitrary change in current and the location of the turns in relation to the height of the tank.

\section{3. Suggested solution to the problem}

The structure of the transformer winding is complex and does not correspond to any known geometry in the strict sense. In general conditions, the transformer windings can be considered cylindrical in shape, therefore, the layers of the windings are a set of nested cylinders [8]. Let's suppose that the heat in the transformer winding is generated at a constant rate, and the oil circulates heat from the windings to the cooling tank. As is known [1], the temperature at different levels of the transformer tank is different, therefore, it is necessary to take into account that the temperature will depend on the spatial variable along the height of the winding. If to consider one cut of a winding with a thickness of one turn as a plate, then this reduces the problem to determining the temperature of one plate, and then a set of plates reflecting the entire winding in height. To simplify calculations, the curvature of the conductor is rejected. The dielectric losses in the insulation will be considered small compared to the losses in the aluminum conductor. The surface of the plates (cut of the winding conductors) will be considered smooth. Let us also assume that the heat from the transformer winding is transferred radially to the cooling medium, we will not take into account the heat transfer from the adjacent winding. 
When constructing a model of heat transfer in such cases, it is important to know the intensity of the volumetric heat release, which is quantitatively characterized by the power of the heat source.

Let's note that for calculations we consider a power oil transformer with a secondary winding made of a rectangular aluminum conductor.

The aim of research. Construction of a model to determine the temperature distribution on the windings of an oil-immersed transformer, as well as to determine the thermal aging of the power winding of a power-oil transformer to predict the service life of the transformer.

\section{Materials and methods}

Let's consider a set of plates (cuts of winding conductors, four conductors are located in the horizontal plane of each cut), the thickness of which is $2 \delta$. A graphic representation of a cut of a plate as an element of a cut from a set of plates is shown in Fig. 1.

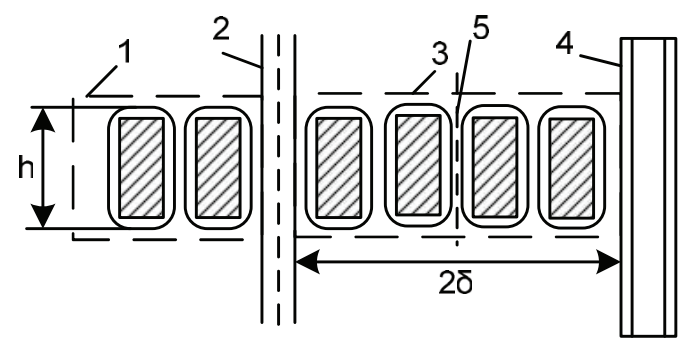

Fig. 1. Cutting a set of conductors in a transformer winding: 1 - high voltage winding;

2 - isolation channel between the windings; 3 - low voltage winding; 4 - magnetic circuit;

5 - center of low voltage winding; $h$ - washing surface, $\mathrm{m}$

Let's note that the heat source is uniformly distributed over the volume of the conductor and is constant. The heat transfer coefficient $\alpha$ and the temperature of the transformer oil of the washing plate $T_{m}$ are given. Let's assume that $\alpha=$ const and $T_{m}=$ const [9].

For stationary processes of heat conduction, the differential equation of heat conduction in the presence of a heat source has the form [9]:

$$
\nabla^{2} T+\frac{q_{v}}{\lambda}=0
$$

where $q_{v}-$ bulk density of the internal heat source; $\mathrm{W} / \mathrm{m}^{3}$,

$\lambda$ - thermal conductivity of the material, $\mathrm{W} / \mathrm{m}$;

$T$ - temperature, ${ }^{\circ} \mathrm{C}$,

$\nabla$ - first-order vector differential operator whose components are partial derivatives with respect to coordinates.

Since our case refers to unsteady heat conduction processes, the differential equation for our case, the equation takes the form [9]:

$$
\frac{\mathrm{d}^{2} T}{\mathrm{~d} x^{2}}+\frac{q_{v}}{\lambda}=0
$$

where $x$ - Cartesian coordinate.

Let's introduce limiting conditions. For $x=$, by expression (1),

$$
\pm \lambda\left(\frac{\mathrm{d} T}{\mathrm{~d} x}\right)_{x= \pm \delta}=\alpha\left(T_{c}-T_{M}\right),
$$

where $T_{c}$-temperature of the outer wall of the conductor, ${ }^{\circ} \mathrm{C} ; \delta$ - plate thickness, $\mathrm{m}$.

Since the boundary conditions for both sides are the same, let's assume that the temperature field inside the plate is symmetric with respect to the plane $x=0$. 


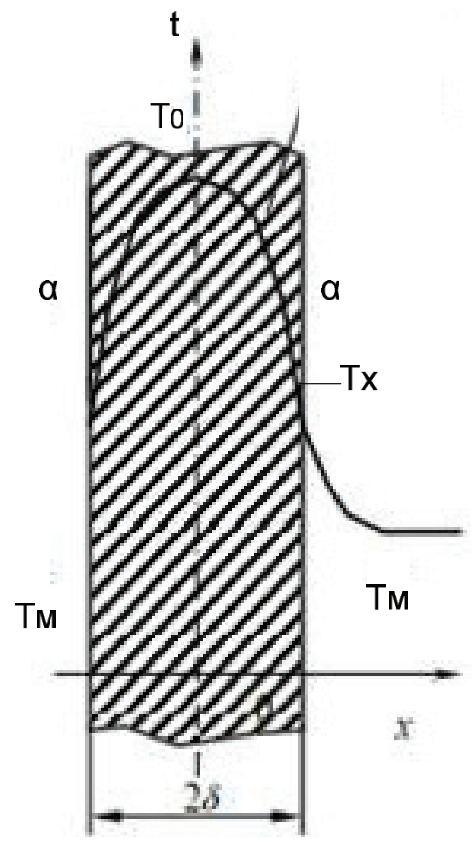

Fig. 2. Thermal conductivity of a flat plate in the presence of internal sources of heat: Tx desired temperature, which appeared as a result of the influence of internal sources of heat

According to Fig. 2, let's consider only one half of the plate (for example, the right one) and write the boundary conditions for it in the form:

$$
\left\{\begin{array}{l}
x=0 ;\left(\frac{d T}{d x}\right)_{x-\delta}=0 ; \\
x=\delta ;-\lambda\left(\frac{d T}{d x}\right)_{x-\delta}=\alpha\left(T_{c}-T_{M}\right) .
\end{array}\right.
$$

After integrating (1):

$$
\begin{gathered}
\frac{\mathrm{d} T}{\mathrm{~d} x}=\frac{-q_{v} x}{\lambda}+C_{1}, \\
T=\frac{-q_{v} x^{2}}{2 \lambda}+C_{1} x+C_{2} .
\end{gathered}
$$

Integration constants $C_{1}$ and $C_{2}$ are determined by the limiting conditions (2). At $x=0$ from equation (3) let's obtain $C_{1}=0$;

From formula (3) let's obtain

$$
\left(\frac{\mathrm{d} T}{\mathrm{~d} x}\right)_{x-\delta}=\frac{-q_{\nu} \delta}{\lambda} .
$$

So

$$
t_{c}=T_{M}+\frac{q_{v} \delta}{\alpha}
$$

Substituting expression (5) into equation (4) at $x=\delta$, let's obtain:

$C_{2}=T_{M}+\frac{q_{v} \delta}{\alpha}+\frac{q_{v} \delta^{2}}{2 \lambda}$. 
Substitute the value of stable integrations $C_{1}$ and $C_{2}$ into expression (4) and find the equation of the temperature field:

$$
T_{x}=T_{M}+\frac{q_{v} \delta}{\alpha}+\frac{q_{v} \delta^{2}}{2 \lambda}\left[1-\left(\frac{x}{\delta}\right)^{2}\right]
$$

To determine the wall temperature of the winding conductor, it is necessary to determine $q_{v}\left(\mathrm{~W} / \mathrm{m}^{3}\right)$ by the formula:

$$
q_{v}=\frac{Q_{v}}{V}
$$

where $Q_{v}$ - heat release in a conductor one meter long, $\mathrm{J} ; V$ - volume of the conductor, $\mathrm{m}^{3}$.

For a more accurate calculation according to formula (5), one should take into account the equivalent thermal conductivity, which is found from the thermal resistance $R_{T}[9]$ :

$$
R_{T}=\frac{\delta}{\lambda}
$$

where $\delta$ - thickness of the entire material layer (m); $\lambda$ - thermal conductivity of the material, W/m.

The equivalent thermal conductivity of the material is found by the formula [9]:

$$
\lambda_{e q}=\frac{\delta_{e}}{R_{T}}
$$

where $\delta_{e}-$ thickness of the entire layer of the material, taking into account the thickness of the metal, insulation and oil channels (m).

Fig. 3 shows a set of transformer winding conductors, top view, as a set of flat plates with rejected winding curvature.

The proposed approach of considering a set of conductors as homogeneous plates is consistent with the mathematical model and does not affect the thermal conductivity.

For a correct assessment of the temperature at the edge of the winding, it is necessary to take into account the natural circulation of oil in the transformer tank. For this, it is necessary to take into account the heat transfer during forced longitudinal washing of a flat surface. Let's emphasize that circulation affects the temperature of the liquid, so the next step is to determine the heat transfer index.

Let's consider the case when the circulation of the liquid is carried out in a natural way. In this case, longitudinal washing is the only convection of heat and acts as a forced longitudinal washing of a flat surface [9].

Let's consider the process of washing the transformer winding to determine the mathematical model, thanks to which obtain the value of the coefficient $\alpha$ required for use in formula (5). For simplicity, let's represent the cylindrical surface of a flat flow of coolant, the speed and temperature of the steel and are denoted by $w_{0}$ and $T_{m}$, respectively. Let's assume that the temperature of the conductor under the influence of the flow of transformer oil directed along the lateral surface of the conductor cut does not change in time, there are no internal sources of heat in the transformer oil, and the frictional heat is neglected.

In order to determine the heat transfer, it is necessary to know the speed distribution of the transformer oil. In work [10], the speed of circulation of transformer oil in the tank was simulated. Therefore, let's take the oil circulation rate in the tank, which is constant and corresponds to the natural oil circulation rate.

Then, according to [9], the heat transfer coefficient has the form:

$$
\alpha=\frac{\lambda}{V_{0}}\left(\frac{d V}{d y}\right)_{y-0}=\frac{3}{2} \times \frac{\lambda}{k} .
$$

where $k$-thickness of the thermal layer, $\mathrm{m} ; V_{0}$ - temperature head, ${ }^{\circ} \mathrm{C}$. 


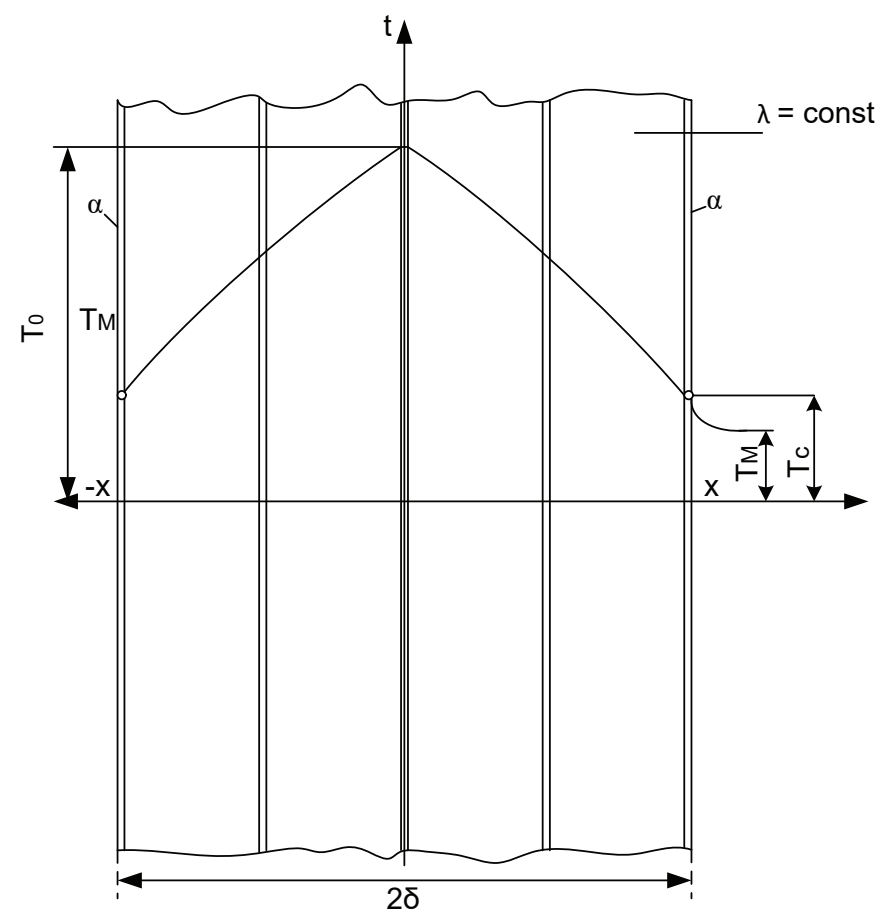

Fig. 3. Division of temperature on four flat plates in the presence of an internal heat source: $T_{0}$ - temperature on the $t$ axis, ${ }^{\circ} \mathrm{C} ; T_{\mathrm{c}}$ - wall temperature, ${ }^{\circ} \mathrm{C}$

According to [9], the thickness of the thermal layer:

$$
k=\frac{4.64 \cdot h}{{\sqrt{\mathrm{Re}_{x}}}^{3} \sqrt{\mathrm{Pr}}} .
$$

where $\operatorname{Pr}$ - the Prandtl number for a liquid, determined from the temperature of the liquid; $\operatorname{Re}-$ the Reynolds number, a dimensionless quantity characterizes the ratio of inertial forces to viscous friction forces in viscous liquids and gases; $h$ - height of the washing surface, $\mathrm{m}$.

According to [9], the Reynolds number:

$$
\operatorname{Re}_{x}=\frac{w_{0} \cdot h}{v}
$$

where $w_{0}$ - fluid circulation rate, $\mathrm{m} / \mathrm{s} ; v$ - kinematic coefficient of viscosity, $\mathrm{m}^{2} / \mathrm{s}$.

Equation (10) is brought into dimensionless form. To do this, multiply the left and right sides by $x / \lambda$ and substitute the value of $k$ in accordance with (11), let's obtain:

$$
\mathrm{Nu}_{h}=0.33{\sqrt{\mathrm{Re}_{h}}}^{3} \cdot \sqrt{\operatorname{Pr}} .
$$

So

$$
\begin{gathered}
\mathrm{Nu}_{h}=\frac{a h}{\lambda}=\frac{a l}{\lambda} \cdot \frac{h}{l}=\mathrm{Nu}_{l} H . \\
\operatorname{Re}_{h}=\frac{w_{0} h}{v}=\frac{w_{0} l}{v} \cdot \frac{h}{l}=\operatorname{Re}_{l} H,
\end{gathered}
$$

where $l$ - length of the conductor along the stream, m; $H$-dimensionless length, $\mathrm{h} / \mathrm{l}$.

The formula for determining the Prandtl number for a liquid has the form [9]: 


$$
\operatorname{Pr}=\frac{v}{\alpha} .
$$

Equation (13) is written in the form:

$$
\mathrm{Nu}_{l}=0.33 H^{-0.5} \operatorname{Re}_{l}^{0.5} \operatorname{Pr}^{1 / 3} .
$$

From (17) it follows that:

$$
\mathrm{Nu}_{l}=\alpha H^{-0.5} \text { or } \alpha=c h^{-0.5} \text {. }
$$

The values $\alpha=0.33 \operatorname{Re}_{h}^{0.5} \operatorname{Pr}^{1 / 3}$ and $c=\alpha \lambda h^{-0.5}$ contain the proportionality coefficient 0.33 , the velocity $w_{0}$, the plate length 1 and the physical parameters $\lambda, v$ and $\alpha$, which do not depend on $h$ [9].

In accordance with (18), at $h=0$, the value of the heat transfer coefficient is infinitely large; with an increase in $h$, it takes on a decreasing final value. This nature of the $\alpha$ configuration is explained by the fact that the flow temperature $\Theta_{0}=T_{M}-T_{x}$ does not change along the surface of the transformer winding, while the temperature gradient on the wall continuously miniaturizes with increasing $h[9]$.

An important component of the study is to determine the duration of the overheating of the conductors in the winding. Let's suppose that the heating time of the winding conductor is short, so we neglect it and take it instantaneous. Let's also assume that the temperature of the transformer oil will be constant due to its natural circulation.

The cooling time of the winding conductor is found by the formula [9]:

$$
\tau=\frac{N C\left(T_{O}-T_{N}\right)}{\alpha F\left(\frac{T_{O}+T_{N}}{2}-T_{M}\right)},
$$

where $M$ - mass of a wire one meter long, $\mathrm{kg}$;

$c$ - heat capacity of the metal, $\mathrm{J} /(\mathrm{kg} \mathrm{K})$;

$T_{o}$ - overheating temperature, ${ }^{\circ} \mathrm{C}$;

$T_{N}$ - normal temperature, ${ }^{\circ} \mathrm{C}$;

$F$ - surface area, $\mathrm{m}^{2}$;

$T_{M}$ - liquid temperature, ${ }^{\circ} \mathrm{C}$.

\section{Results}

Let's check the correctness of the approach and construction of models by the method of conducting a numerical experiment. Let's use the data on the circulation of transformer oil from [10] for the heat transfer model, which reflects the results of modeling the speed of circulation of the transformer oil inside the tank.

Let's take from work [11] the input data, the type and nominal parameters of the studied transformer:

- transformer TRD-16000/35;

- rated line current of the secondary winding $254 \mathrm{~A}$;

- overload current (critical conditions) 508 A;

- secondary winding made of rectangular aluminum conductor.

Let's determine the heat dissipation from one meter of an aluminum conductor having a rectangular slot with sides 4 and $9 \mathrm{~mm}$.

The volume of aluminum is determined by the formula:

$$
V=l_{c} \cdot S_{c}
$$

where $l_{c}$ - length of the conductor, $1 \mathrm{~m} ; S_{c}$ - conductor cross-sectional area, $\mathrm{m}^{2}$;

The heat dissipation in one meter of the conductor is determined by the formula: 


$$
Q_{v}=I^{2} \cdot R_{a l} .
$$

where $R_{a l}$ - resistance of aluminum, Ohm; $I$ - current flowing through the conductor, A;

Having calculated all the necessary coefficients, according to (6), let's obtain the calculation results for $x=\delta$. The numerical results of the study are shown in Table $\mathbf{1}$.

Table 1

Research results for the winding edge

\begin{tabular}{ccc}
\hline Load in relative units & $\boldsymbol{T}_{\boldsymbol{M}},{ }^{\circ} \mathbf{C}$ & $\boldsymbol{T}_{\boldsymbol{r}},{ }^{\circ} \mathbf{C}$ \\
\hline 1 & 80 & 88.2 \\
1.1 & 80 & 90 \\
1.2 & 80 & 92 \\
1.3 & 80 & 96 \\
1.4 & 80 & 99 \\
1.5 & 80 & 101 \\
1.6 & 80 & 104 \\
1.7 & 80 & 107 \\
1.8 & 80 & 110 \\
1.9 & 80 & 113 \\
2 & 80 & 117 \\
2.1 & 80 & 121 \\
2.2 & 80 & 124
\end{tabular}

According to the tabular data in Fig. 4 graph of the dependence of the temperature of the transformer winding on the current value

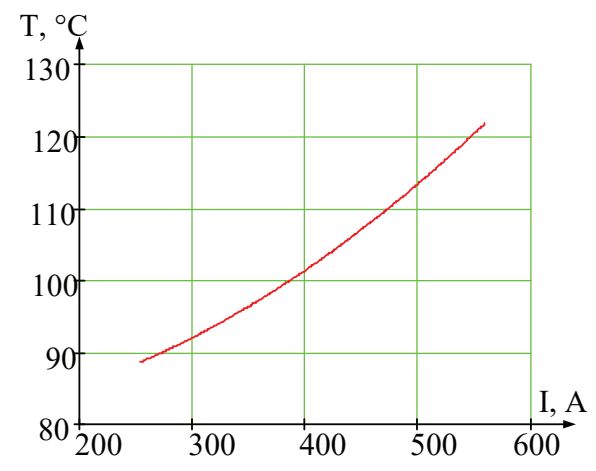

Fig. 4. Graph of the dependence of the temperature at the edge of the transformer winding on the current value

According to (6), such a calculation of the temperature was made at $x=0$. The numerical results of the study for the middle of the winding are given in Table 2.

According to (6), a three-dimensional graph of temperature changes is built depending on the distance from the center of the winding, Fig. 6. Let's note that at $\delta=0$, this is the middle of the winding and $\delta=0.012$ is the investigated edge of the winding, the current $I(\%)$ is indicated in relative units of the nominal, where 1 is $100 \%$ of the load, and 1.2 is $120 \%$ of the nominal load of the investigated transformer.

According to (19), let's calculate the duration of cooling the conductor wall to a normal temperature of $95^{\circ} \mathrm{C}[11]$.

The graphic result of the study of the duration of the conductor cooling to normal temperature is shown in Fig. 7. Calculation according to (19) shows that the cooling time is not linear. For a complete understanding, let us consider an example of one short-term load jump, when, according to (19), we calculate the cooling time at an overheating temperature of $150^{\circ} \mathrm{C}$, in Fig. 7 is point 1. That is, it takes about 500 seconds to cool from $150^{\circ} \mathrm{C}$ to $95^{\circ} \mathrm{C}$, and 100 seconds after the start of cooling, the temperature will be about $130^{\circ} \mathrm{C}$. Thus, knowing the time intervals when the tem- 
perature of the winding will be higher than the rating data, we can determine with an accuracy of a second when the transformer winding loses its insulating resource.

Table 2

Research results for the middle of the winding

\begin{tabular}{ccc}
\hline Load in relative units & $\boldsymbol{T}_{\boldsymbol{M}},{ }^{\circ} \mathbf{C}$ & $\boldsymbol{T}_{\boldsymbol{x}},{ }^{\circ} \mathbf{C}$ \\
\hline 1 & 80 & 98 \\
1.1 & 80 & 101 \\
1.2 & 80 & 105 \\
1.3 & 80 & 110 \\
1.4 & 80 & 114 \\
1.5 & 80 & 119 \\
1.6 & 80 & 125 \\
1.7 & 80 & 131 \\
1.8 & 80 & 143 \\
2 & 80 & 150 \\
2.1 & 80 & 157
\end{tabular}

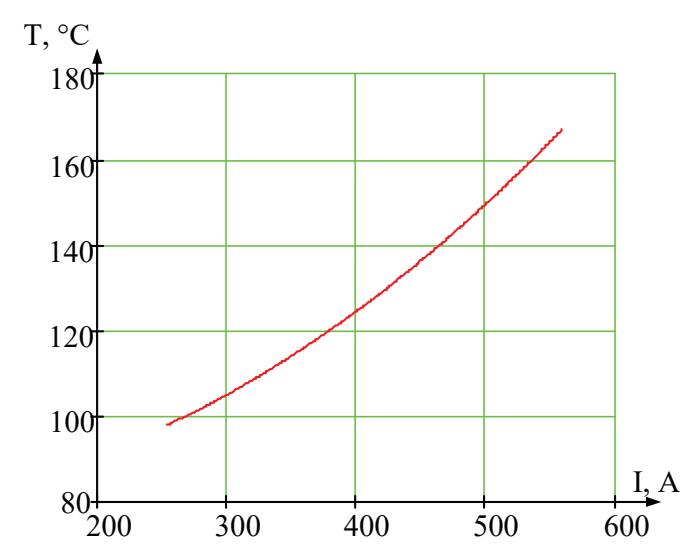

Fig. 5. Graph of the dependence of the temperature in the middle of the transformer winding on the current value

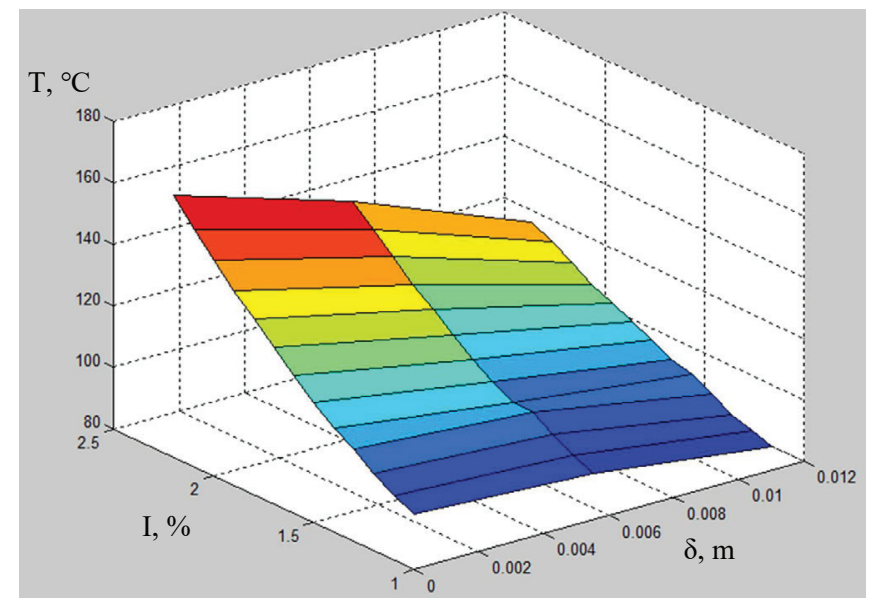

Fig. 6. Graph of the temperature field of the insulation of the winding of the power transformer depending on the current in relative units $I(\%)$ flowing through the winding, and the distance from the middle of the winding to its edge $\delta(\mathrm{m})$ 


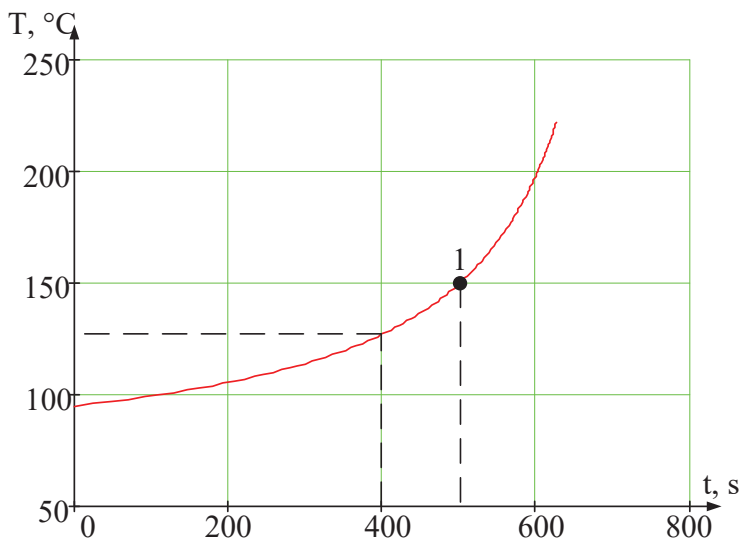

Fig. 7. Graphical dependence of the cooling duration of one meter of the winding wire

Simulation of load outlines is carried out, the nature of which is shown in Fig. 8a. According to (19), a graph of the winding temperature distribution is plotted as a result of short-term loads in real operation.

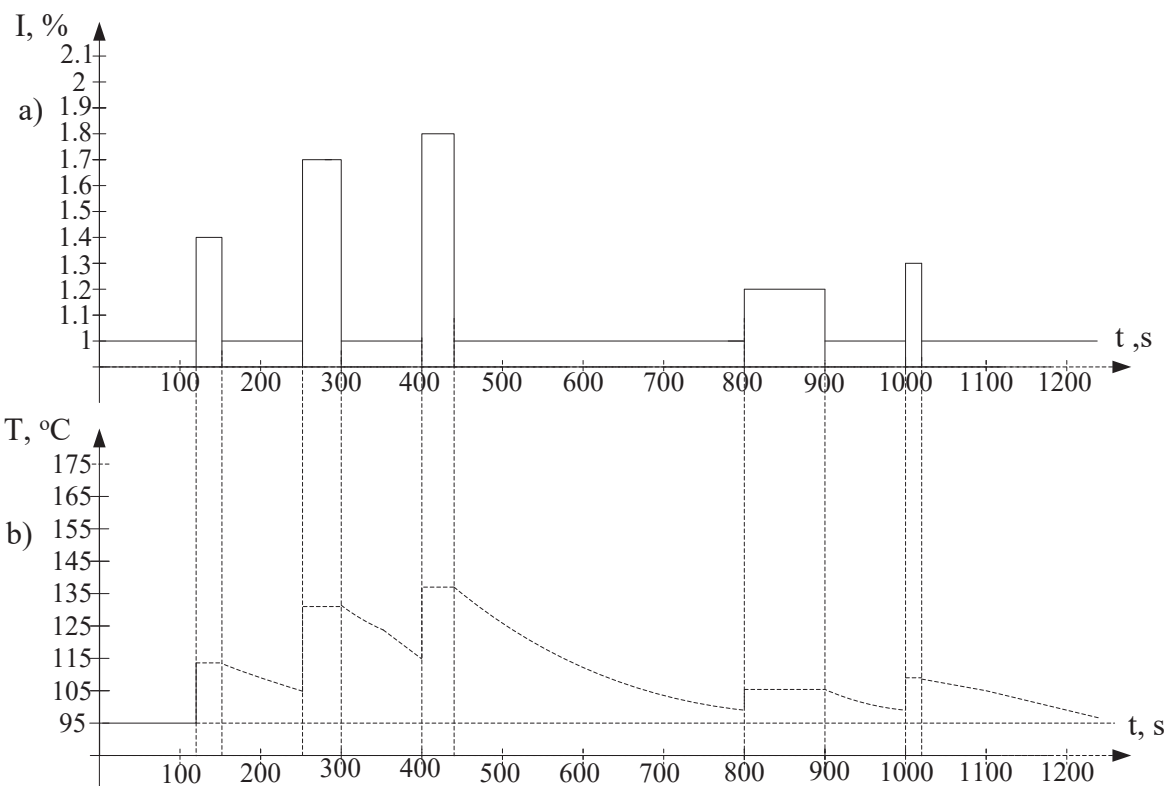

Fig. 8. Result of simulation of load surges: $a$-graph of short-term loads; $b$-graph of temperature distribution depending on the load nature

\section{Discussion of research results}

The proposed approach, even taking into account the selected assumptions, quite accurately reflects the nature of heat distribution in the transformer winding in different operating modes. This temperature distribution model shows that the hottest point is in the middle of the winding. The results of the study of determining the temperature distribution in the winding of a power oil transformer are presented in Fig. 4-6. It can also be seen from the results of the study that the temperature field of the transformer winding is inhomogeneous and changes with increasing distance from the middle of the winding. The results obtained agree with the known experimental results [7, 12-15]. It can be seen that they have the same character of change, which indicates the adequacy of the calculation model. It should be noted that the work [7] does not take into account the temperature distribution of the transformer oil in relation to the winding height. In our model, the specified temperature is taken into account. Obviously, the higher the conductor in the winding, the higher the oil temperature will be, which will lead to increased heating, and vice versa, the lower the conductor is, the lower the temperature will be during overload. 
Fig. 8 shows the result of applying the calculated model with the determination of the duration of overheating at short-term overloads. It has been determined that the data make it possible to assess how to build a system for predicting the aging of insulation in the windings of powerful power transformers.

The results of this work, obtained under the condition of using a number of simplifications, namely, the thermal effect of the high voltage winding and the magnetic circuit was not taken into account, the thermal effect of the winding turns located above and below the investigated layer of conductors was also not taken into account, therefore, to more accurately determine the temperature distribution, the work will continue over improving the model.

In the next work, it is planned to improve the model for determining the temperature of the winding of a power transformer by taking into account the effect of a high voltage winding, a magnetic circuit and turns located above and below the investigated layer.

\section{Conclusions}

In this work, a thermal model has been built to determine a hotter point in the winding of a power transformer. The adequacy of the model was verified for a $16000 \mathrm{kVA}$ transformer.

The paper provides an example of calculation for one layer of conductors in the transformer winding, however, this method allows for each layer of conductors to determine the temperature of the winding and the degree of thermal aging, taking into account short-term load surges.

The problem of calculating the temperature in the winding of an oil-immersed transformer, taking into account short-term load surges, has been solved. The constructed mathematical model of the application of which makes it possible to determine the temperature distribution from the center of the winding to the extreme turns washed by the transformer oil by the load appearing in the transformer. The calculated temperature distribution can be used to predict the thermal aging of the insulation of the transformer windings.

According to the research carried out, it is possible to determine the degree of thermal aging for any type of oil transformer.

\section{References}

[1] Lizunova, S. D., Lokhanina, A. K. (2004). Silovye transformatory. Spravochnaia kniga pod redaktsiei. Moscow: Energoizdat, 616.

[2] Hrabko, V. V., Balzan, I. V. (2012). Pat. No. 69641 UA. Device for diagnostics of a power oil transformer. MПК: G01R31/06. No. u201111889; declareted: 10.10. 2011; published: 10.05.2012; Bul. No. 9, 14.

[3] Hrabko, V. V., Balzan, I. V. (2012). Pat. No. 69642 UA. Device for diagnostics of a power oil transformer. MПК: G01R31/06. No. u201111890. declareted: 10.10.2011; published: 10.05.2012; Bul. No. 9, 14.

[4] Radakovic, Z. (2003). Numerical determination of characteristic temperatures in directly loaded power oil transformer. European Transactions on Electrical Power, 13 (1), 47-54. doi: http://doi.org/10.1002/etep.4450130107

[5] IEEE Loading Guide for Mineral Oil Immersed Transformer (1995). C57.91, 112.

[6] IEEE Guide for Determination of Maximum Winding Temperature Rise in Liquid-Filled Transformers (2000). IEEE Std. 1538-2000. doi: http://doi.org/10.1109/ieeestd.2000.91904

[7] Taghikhani, M. A., Gholami, A. (2009). Prediction of hottest spot temperature in power transformer windings with non-directed and directed oil-forced cooling. International Journal of Electrical Power \& Energy Systems, 31 (7-8), 356-364. doi: http:// doi.org/10.1016/j.ijepes.2009.03.009

[8] Pradhan, M. K., Ramu, T. S. (2003). Prediction of hottest spot temperature (hst) in power and station transformers. IEEE Transactions on Power Delivery, 18 (4), 1275-1283. doi: http://doi.org/10.1109/tpwrd.2003.817739

[9] Isachenko, V. P., Osipova, V. A., Sukomel, A. S. (1981). Teploperedacha. Moscow: Energoizdat, 417.

[10] Kazanskyi, S. V., Pekur, P. P. (2017). Features load capacity assessment of power transformers in the wind power plants. Vidnovliuvana enerhetyka, 1, 49-55.

[11] Tikhomirov, P. M. (1986). Raschet transformatorov. Moscow: Energoizdat, 528.

[12] Ruan, J., Deng, Y., Huang, D., Duan, C., Gong, R., Quan, Y. et. al. (2020). HST calculation of a 10 kV oil-immersed transformer with 3D coupled -field method. IET Electric Power Applications, 14 (5), 921-928. doi: http://doi.org/10.1049/iet-epa.2019.0469

[13] Gao, S., Liu, Y., Li, H., Sun, L., Liu, H., Rao, Q., Fan, X. (2020). Transformer Winding Deformation Detection Based on BOTDR and ROTDR. Sensors, 20 (7), 2062. doi: http://doi.org/10.3390/s20072062

[14] Liu, Y., Tian, Y., Fan, X., Bu, Y., He, P., Li, H. et. al. (2018). A Feasibility Study of Transformer Winding Temperature and Strain Detection Based on Distributed Optical Fibre Sensors. Sensors, 18 (11), 3932. doi: http://doi.org/10.3390/s18113932

[15] Arabul, A. Y., Senol, I. (2017). Development of a hot-spot temperature calculation method for the loss of life estimation of an ONAN distribution transformer. Electrical Engineering, 100 (3), 1651-1659. doi: http://doi.org/10.1007/s00202-017-0641-0 